\title{
Politicians as Experts, Electoral Control, and Fiscal Restraints*
}

\author{
March 7, 2012
}

\begin{abstract}
We establish an argument for fiscal restraints which is based on the idea that politicians are experts in the meaning of the credence good literature. A budget maximizing politician is better informed than the electorate about the necessary spending to ensure the states ability to provide services for the economy. Voters, being able to observe the budget but not the necessary level of spending, attenuate the government's spending level via electoral control. A fiscal restraint limits the maximum spending a government will choose if the level of spending ensuring the politicians reelection is not sufficient to ensure the state's ability to provide services to the economy. We determine when such a fiscal restraint improves voter welfare and discuss the role of the opposition in situations where very high levels of spending are required.
\end{abstract}

JEL classification: D82, H50, H61

Key words: Electoral control, Fiscal restraints, Credence goods

${ }^{*}$ We are grateful for comments by Kai Konrad, Jianpei Li, Jayanta Sarkar and Magnus Wikström. 


\section{Introduction}

The recent debates about restraining government budgetary policies, whether in the form of European style balanced budget rules or in the form of American debt ceilings are controversial. While supporters of such restraints cite externalities on future generations as well as on other countries, opponents argue that such rules limit the ability of governments to intervene in times where major interventions are needed, which may come at very high costs for society. ${ }^{1}$ We provide an analysis of the welfare costs and benefits of such rules under the assumption that politicians, with an interest to maximize the budget, serve as experts or specialists, i.e., they are better informed about the public spending necessary to handle public affairs given the current state of the economy. Fiscal restraints are an instrument complementing electoral control to limit rents politicians can extract but they limit politicians' ability to deal with shocks requiring very high levels of public spending.

Our argument is new as we view government as political experts or specialists mandated by the people to look after the public affairs. In this sense, politicians serve a similar role as doctors, lawyers or other experts. If a person feels sick, he or she consults a doctor to identify the cause as well as potential cures. In most cases the patient is not able to check upon neither the diagnosis nor the choice of the cure. The doctor due to her education and experience has the expertise to make this decision. The relationship between the people and politicians can be seen in a similar way. The politician specializes in understanding public affairs and additionally has governmental resources at her disposal to identify the need for necessary policy interventions. These policy decisions are needed to ensure that the people are able to derive a utility from the functioning of the state. Similar to the example of the doctor, the people are often not able, due to a lack of

\footnotetext{
${ }^{1}$ These two positions are particularly present in the current debate on the austerity and rescue plan for the Greek government, that is commonly supervised by the European Commission, the European Central Bank and the International Monetary Fund. For a general discussion on the pros and cons of fiscal restraints see, e.g., Schick (2010).
} 
information and experience, to check upon the decisions of politicians. ${ }^{2}$ To relate to recent policy debates, most voters cannot determine whether the downturn of the economy is a normal movement along the business cycle or whether it is a severe economic crisis and what size of macroeconomic policy intervention is required to overcome these problems. While no one may have the perfect answer, politicians do have access to substantial analysis and data to make an informed decision. Similar in the case of foreign and defense policy, many voters are not able to determine the severity of external threats to the country and which level of defense spending and international involvement in conflicts is necessary to reduce these threats.

The theoretical literature on industrial economics has studied extensively the role of and the incentives for experts-like doctors or specialists in general (see Dulleck and Kerschbamer, 2006, for a survey). The goods and services provided by experts are referred to as credence goods, as the customer needs to trust the provider to choose the appropriate action given the state of the world. To view the services of politicians as credence goods has not been considered in the literature. The present article attempts to close this gap by assuming that politicians are in the role of experts serving the people who elected them. In doing so we want to study its implication for the analysis of fiscal policy, in particular the role of constitutional fiscal restraints.

The informational asymmetry between the people and their politicians would be of no concern, if the interests of both parties would be perfectly aligned. We do not make this assumption. Instead we assume, in line with the public choice tradition following Buchanan (1967), that politicians are self-interested rational agents who systematically pursue their own goals looking for rents from their expertise. Drawing the parallels to doctors again, the politician's as well as the

\footnotetext{
${ }^{2}$ Clearly, the analogy to a doctor is imperfect. From the voters perspective, it is impossible to consult a second expert while it is a possibility for a patient. Also, from the politician's perspective, the threat of not being reelected is more severe compared to the threat of the doctor who may lose one patient but still has a large number of patients to serve. What we want to focus on is that the informational asymmetry and the incentives involved are similar.
} 
doctor's incentive may be to go for more costly actions instead of the most efficient one. In a sense, the doctor as well as the politician benefits from large spendings on their activities. While this incentive may be purely monetary in case of doctors, for politicians the reward maybe recognition and gratitude from beneficiaries that come with large budgets. In this sense we follow the argument Niskanen (1971) made about bureaucrats and assume that politicians are interested in maximizing public spending.

The people, as the tax payers that have to finance the budget, can use two mechanisms to discipline the spending of elected politicians. On the one hand, they can exert electoral control, that is, they can vote a politician out of office if her expenditure appears to be too excessive. From the perspective of a politician this implies a loss of future rents from holding office. Therefore, people's electoral behavior can incentivize politicians to act in the interest of the people. This argument has been put forward by Barro (1973) and Ferejohn (1986) in their work on political accountability. On the other hand, the people can restrain the actions of politicians by constitutional rules, for example budget limits. The role of such limits on fiscal policy has been emphasized in particular by Brennan and Buchanan (1980).

Our model shows that both mechanisms, the threat of not being reelected as well as spending limits have a cost for society. Consider first the cost of electoral control. To use this as an incentive, the electorate has to choose a critical level of spending such that the politician is not reelected if her budget choice exceeds this level. This already allows the politician to spend more than necessary in times the necessary spending is below the critical level. Such a rent cannot be avoided even without the informational asymmetry between voters and politicians. It follows purely from the fact that the people have to entrust politicians with the power to spend. In case of asymmetric information such a reelection rule implies that if the efficient spending level, given the true state of the world, exceeds the critical level, then the politician has to expect to loose office and therefore has an incentive to maximize spending. The reason for this is that in such a situation either the 
government spends more than the reelection level so that public affairs are handled but the politician is not reelected or-if she chooses a lower level of spending-that public affairs are not dealt with appropriately. The latter needs to be punished as well as this should be avoided if it is very costly for the people-these costs may for example be the need to enter a war not being prepared for it or entering a long lasting recession. In this article we identify optimal reelection rules taking this cost of incentivizing expert politicians into account.

Consider next the cost of constitutional spending limits. Such a limit reduces the maximum spending that can occur if a politician does not expect to be reelected. However, it also implies that in some cases politicians are not able to ensure that public affairs are handled. In expectation, these costs are the higher, the more likely it is that very high levels of public spending are needed, as avoidable crises become more frequent in this case. We are able to characterize a condition when such a constitutional spending limit improves voter welfare under the assumption that the constitution does not allow any exemption from the spending limit. The condition is as intuitive as it is restrictive: Introducing a spending limit is optimal, if and only if the probability of the state of the world that requires very high levels of spending is small relative to the loss in utility that the people experience if public affairs cannot be dealt with. For supporters of constitutional spending limits, this should be bad news as it is likely that the loss of utility may be large and the probability of severe spending requirements may be seen as non-negligible. Most rules currently discussed specify exemptions that allow politicians under certain circumstances to exceed the limit. ${ }^{3}$ We analyze rules with exemptions in an extension of the model and show that these can improve voter welfare independent of the probability that high levels of spending are re-

\footnotetext{
${ }^{3}$ To give just one example: The German constitution specifies in Article 115 (2) a balanced budget rule and then states "... In cases of natural catastrophes or unusual emergency situations beyond governmental control and substantially harmful to the state's financial capacity, these credit limits may be exceeded on the basis of a decision by a majority of the Bundestag's Members." Similar amendments to the constitutions have been made in other European countries, e,g. Switzerland and Spain, or are currently on the political agenda in most member states of the European Union. Also, most US states have some form of a balanced budget or spending rule that allows for exemptions.
} 
quired. However, if such an exemption allows the politician in power to determine whether these circumstances apply, or, equivalently, if a governing majority is sufficient to call upon an exemption as most existing fiscal rules in Europe and the US imply, we are back to a situation without a spending limit. For this reason we analyze a rule where an exemption can only be triggered if the opposition agrees that the circumstances apply. We specify a game where the electorate, the government and the opposition behave rational. The opposition wants to oust the government and, similar to the government, has access to information about public affairs and the required level of spending. We show that a constitutional spending limit that requires support by the opposition in case of a government exceeding the spending limit always improves voter welfare. We characterize the optimal electoral behavior of voters such that the opposition agrees to the government exceeding the spending limit if and only if this is required by the true state of the world.

The remainder of the paper is organized as follows. Section 2 discusses the related literature and further elaborates on the key idea of this paper. Section 3 introduces the model. Section 4 characterizes the equilibrium public budget in a benchmark scenario with full information. Section 5 then establishes the equilibrium budget with expert politicians. Section 6 introduces a fiscal restraint on the public budget and identifies the conditions under which such a restraint improves voter welfare. Section 7 considers the role of the opposition in applying a fiscal restraint. Section 8 concludes.

\section{Related Literature}

While this paper provides an agency argument why fiscal restraints on government spending can be welfare increasing, an existing literature on such restraints focusses on problems of externalities, either affecting future generations or affecting other countries. The existing theoretical explanations for such policy interventions based on intergenerational equity arguments assumes an externality given that the current generations of politicians and voters decide about how much to borrow, 
inflating the benefit and discounting the restrictions this imposes on future generations more than it is deemed to be equitable. The externality stems from the assumption that the current generation does not internalize, in a Ricardian sense, the cost it imposes on future generations. This assumption applies if not everyone in a society cares about the next generation-some may simply have no children to care about (Buchanan and Tullock, 1962). An alternative story, leading to a similar outcome, is that current governments may overspend strategically to limit the manoeuverability of a future government if the incumbent does not expect to be reelected (Persson and Svenson, 1989, Tabellini and Alesina,1990). Apart from these intergenerational arguments, von Hagen and Eichengreen (1996) look at stabilization policies arguing that fiscal restraints may be needed to limit fiscal externalities on countries with close ties to the economy in question, in particular in the case of a currency union.

In the presence of any externality-whether intergenerational or between countries-inefficient allocations may result, even if preferences of politicians and (concurrent) voters are perfectly aligned, i.e., no agency problems exist. Our model is based on the assumption of infinitely lived voters in a (closed) economy, hence we explicitly abstract from intergenerational as well as international externality issues. In this sense the argument for fiscal restraints established in this paper is complementary to the existing literature emphasizing externalities.

As indicated above we add the analysis of fiscal restraints to the discussion of agency problems of government-a literature that started with Barro (1973) under the heading of political accountability. Barro (1973) showed that if preferences of the government and its electorate are not perfectly aligned then the electorate has to offer the incumbent some rent of holding office to incentivize the government not to pursue its own goal because it will be voted out of office for sure. As Barro, we rule out any intergenerational or cross-national externalities by assuming that voters are Ricardian in the sense of taking into account any future tax payments that have to be paid given a government's budget decision. We identify the rent from power that has to be offered to incumbents to incentivize them not to exploit 
their position. Where Barro assumed perfect information, Ferejohn (1986) added asymmetric information. In Ferejohn's model, the electorate cannot observe the activities of the government but is only able to assess the government's performance. The electorate thus needs to incentivize politicians by a reelection rule to act in the interest of the public.

Persson et al. (1997) elaborate on Ferejohn's approach by analyzing how the separation of powers can help to elicit information on government activities and contain rent seeking behavior of politicians. We differ from this literature by setting up the information problem as a credence good problem. Voters can observe the budget chosen by the government and they can observe its effect on their own well-being. However, voters cannot fully assess whether the extent of the budget was necessary to achieve this outcome. Only politician can observe the true state of the world and this state determines the minimum necessary government budget. Similar to Persson et al. (1997) we are able to distinguish between a Barro type rent from power and an information rent of the politician. Furthermore and more importantly, we are able to present a rational for a constitutional fiscal restraint as an instrument to limit the Barro type as well as the information rent of incumbents.

Fiscal restraints are a common theme in the public choice literature, classic examples being Brennan and Buchanan (1980) and Wilson (1989) using a Leviathan concept of government in which politicians just maximize the size of the budget and electoral pressure does not limit this tendency. The only article, to our knowledge, discussing fiscal restraints with an agency perspective on government is Besley and Smart (2007). These authors study the role of fiscal restraints in the presence of moral hazard and adverse selection where politicians can be either good, i.e., always work in the interest of the electorate, or bad, i.e., pursuing self-serving concerns. The latter are able to divert rents as the incumbent has information about the cost of the public good. Fiscal restraints in this model are used to select the right politicians as well as to limit rents extracted by bad incumbents. One interesting finding is that introducing fiscal restraints may only be welfare enhancing if the frequency of bad politicians is low. We differ from this model 
by assuming the information asymmetry based on the credence goods perspective (see Darby and Karni, 1973, for the classic reference, Dulleck and Kerschbamer, 2006, for a survey of the theoretical literature and Dulleck et al., 2011, for experimental evidence). We provide reasons for implementing constitutional rules that limit government spending without assuming an adverse selection problem with respect to the types of politicians that run for office. Furthermore,we are able to show that fiscal restraints are welfare diminishing if the probability of severe cost shocks to the economy are relatively large.

Another paper that is related to our approach is Yared (2010). This author assumes pure rent seeking politicians who are able to extract rents due to temporary economic shocks. These shocks generate changes in tax revenue and in the need for expenditure thus allowing governments to build up a tax base that can be diverted for rent appropriation. In the model the voters reelection decision puts restrictions on taxes levied as well as minimum levels of public spending. While a benevolent government would impose constant tax rates to limit the excess burden of taxation, taxes with rent seeking politicians will be volatile as citizens trade off the benefit of constant taxes with the cost of potential appropriation by the government. We differ from Yared by studying a problem of asymmetric information where only a too limited budget can be identified by the electorate. Furthermore, we explicitly discuss the role of fiscal restraints.

\section{The Model}

Time is discrete and divided into legislative periods. In each legislative period $t$, public affairs require a budget of at least $\theta_{t}$ currency units. The variable $\theta_{t}$ is randomly drawn from the interval $[0, \bar{\theta}]$. We assume that $\theta_{t}$ is identically distributed and serially uncorrelated over time, with continuous density $f$ and cumulative distribution function $F{ }^{4}$

\footnotetext{
${ }^{4}$ This may look like a strong assumption in a model for the case of macroeconomic stabilization requirements. One may argue that over one time period of the model-one voting cycle-this assumption is not too critical. What we need is that the shock in each period is uncorrelated to the
} 
If the public budget in period $t$, denoted by $b_{t}$, is smaller than $\theta_{t}$, public affairs cannot be handled appropriately and this has a negative impact on the welfare of the electorate. In contrast, if the public budget at time $t$ equals or exceeds $\theta_{t}$, public affaires can be treated appropriately, but the exceeding amount $b_{t}-\theta_{t}$ is slack in the sense that it does not contribute to the electorate's welfare. ${ }^{5}$ We assume that the public budget is bounded from above, so that $b_{t} \leq \bar{\theta}$ in each legislative period $t$. This implies that the public budget can never exceed the largest amount possible, that is required to handle public affairs. Note that we do not limit the budget otherwise, i.e., we assume that the state's financial base-tax base as well as access to financial markets-is sufficient to deal with any possible budgetary need. Moreover, we do not distinguish between tax and debt financed public funds. Since voters will be assumed to face an infinite time horizon, they fully internalize future tax burdens associated with current deficits. As a consequence, voters are indifferent between tax and debt financed public funds and only care about the level of public spending.

The electorate consists of a unit-measure continuum of identical and infinitely lived voters. The representative voter's intertemporal expected utility in period $t$ is given by

$$
V_{t}=E \sum_{j=0}^{\infty} \delta^{j} v\left(b_{t+j}, \theta_{t+j}\right),
$$

where $\delta$ represents a discount factor commonly employed by both voters and incumbent politicians, $E$ is the expectations operator, and $v$ denotes the singleperiod utility of the representative voter which depends on the size of the public budget and the realization of $\theta$ in this period. The representative voter's single-

shocks in previous periods.

${ }^{5}$ Our assumption of a discrete jump in voter utility if public spending is higher than the critical level is a simplification. Essential for our argument is that below the critical level as well as above this level the marginal benefit to voters is smaller than 1, i.e., the cost to voters is higher than the benefit of each dollar spent. If the critical level of spending is reached, the state delivers all the essential services and hence at this point voters experience a discrete jump in utility. 
period preferences are defined as

$$
v\left(b_{t}, \theta_{t}\right)= \begin{cases}\phi-b_{t}, & \text { if } \quad b_{t} \geq \theta_{t} \\ -b_{t}, & \text { if } \quad b_{t}<\theta_{t}\end{cases}
$$

Thus, if the public budget is sufficiently large to handle public affairs appropriately, the representative voter enjoys a benefit amounting to $\phi>\bar{\theta}$ and, at the same time, forgoes private consumption in an amount equal to the public budget. The assumption $\phi>\bar{\theta}$ implies that it is always efficient to handle public affairs appropriately. If, in contrast, the public budget is too small to handle public affairs, the representative voter receives no benefit from public finance and only forgoes private consumption in an amount equal to the public budget.

The incumbent politician's intertemporal expected utility in period $t$ reads

$$
U_{t}=E \sum_{j=0}^{\infty} \delta^{j} b_{t+j}
$$

that is, the incumbent is assumed to be a budget maximizer. Generally, a politician can be reelected infinitely often. However, only during incumbency the politician directly derives utility from the size of the public budget. Once voted out of office, the politician's preferences are similar to that of (other) voters. We assume that in the event an incumbent is thrown out of office, the incumbent is replaced by another politician and is never reappointed. ${ }^{6}$ Alternate politicians are always available who, once in office, pursue the same objective-maximizing the public budget-as their predecessors.

Voters employ a specific voting rule in order to control the budget maximizing behavior of the incumbent. At the beginning of each legislative period $t$ voters bind themselves to a voting rule that they will follow at the end of the legislative period. This rule conditions their voting behavior on the information they gather within the legislative period. The incumbent is aware of the voting rule. Then, nature decides on the realization of $\theta_{t}$ and, hence, on the minimum size of the

\footnotetext{
${ }^{6}$ Persson et al. (1997) employ a similar assumption. Ferejohn (1986) considers this case as well as the case that a politician may return.
} 
public budget, necessary to handle public affairs. In the full information scenario both voters and the incumbent observe $\theta_{t}$, whereas in the asymmetric information scenario $\theta_{t}$ is only revealed to the incumbent. Once the incumbent has learned the realization of $\theta_{t}$, she chooses the budget $b_{t}$. Finally, voters either reelect the incumbent or vote her out of office based on the voting rule, they have committed to at the beginning of the legislative period. If the incumbent is voted out, she is replaced by a new incumbent who has the same budget maximizing attitude and is also in all other respects identical to the incumbent.

We follow Ferejohn (1986) and Persson et al. (1997) in determining the voting equilibrium. The assumption of ex ante commitment to a voting rule is a sequential equilibrium, i.e., voters have no incentive to change the rule at the end of the legislative period, if they are indifferent between the incumbent and an opposing politician. Note that voters only commit to a voting rule within a single legislative period. That is, voters cannot commit to voting behavior in future legislative periods. Instead, when deciding on the voting rule, current voters take into account that voting behavior in future periods must be in the interest of the electorate at that time. Figure ?? illustrates the sequence of events within a single legislative period.

\section{FIGURE 1}

In the following, we first assume that both the incumbent and the voters observe the state of nature $\theta_{t}$ at each period $t$. This serves as a benchmark to distinguish between the rents the incumbent extracts from pure office holding and the rents that are associated with private information of the incumbent. A further reason to consider the full information scenario is to assume the existence of an opposition that has access to the same level of information as the incumbent and is able to reveal this information credibly to the public. We then consider the more relevant case that the incumbent can observe $\theta_{t}$ whereas voters cannot. In this case, the incumbent is said to be an expert politician. With respect to the existence of an opposition with similar expertise, the assumption of private information of the incumbent implies that the opposition cannot credibly com- 
municate this information to the public. For the case of asymmetric information we consider situations with and without fiscal restraints. We show that while the welfare implications of a fiscal restraint that does not allow for any exemptions are mixed, a fiscal restraint that allows for such exemptions can be deployed in a strictly welfare improving way. This becomes possible if breaking a fiscal restraint requires approval by the opposition. Though the opposition cannot credibly communicate its expertise information to voters, the equilibrium behavior of the opposition when (not) approving of a break of the fiscal restraint still contains reliable information for voters to exert electoral control more effectively.

\section{Full Information Equilibrium}

If both, the incumbent and the voters can observe $\theta_{t}$, voters can easily commit to vote out the incumbent if either $b_{t}>\theta_{t}$ or $b_{t}<\theta_{t}$, the latter implying $v\left(b_{t}, \theta_{t}\right)=$ $-b_{t}$. In the former case the incumbent has chosen a budget larger than necessary to handle public affairs and in the latter case a budget smaller than necessary. While the latter case can generally be ruled out by the incumbent's inclination to choose a larger rather than a smaller budget, the former case needs to be considered just because of this inclination. In fact, a strict rule to vote the incumbent out of office if $b_{t} \neq \theta_{t}$ is generally not optimal as if $\theta_{t}$ turns out to be small, the incumbent would prefer to choose $b_{t}=\bar{\theta}$ and being thrown out of office at the end of the legislative period, rather than striving for another term in office by choosing $b_{t}=$ $\theta_{t}$. In order to weaken the incumbent's incentives to choose a maximum budget when she observes a small $\theta_{t}$, voters must allow the incumbent a certain minimum budget. Let the minimum budget in legislative period $t$ be denoted by $\hat{b}_{t}^{f}$, with superindex $f$ indicating the full information scenario. Then, the reelection rule in legislative period $t$ specifies that voters reelect the incumbent if she spends at most the budget $\hat{b}_{t}^{f}$, for the case that $\theta_{t}$ turns out to be small, i.e., $\theta_{t} \leq \hat{b}_{t}^{f}$. Furthermore, the reelection rule in legislative period $t$ specifies that voters reelect the incumbent if $b_{t}=\theta_{t}$ for the case that $\theta_{t}>\hat{b}_{t}^{f}$. Given that voters aim to minimize spending 
and politician's incentive, the minimum budget $\hat{b}_{t}^{f}$ is implicitly determined by

$$
\hat{b}_{t}^{f}+\sum_{j=1}^{\infty} \delta^{j} \hat{b}_{t+j}^{f} F\left(\hat{b}_{t+j}^{f}\right)+\sum_{j=1}^{\infty} \delta^{j} \int_{\hat{b}_{t+j}^{f}}^{\bar{\theta}} \theta_{t+j} d F\left(\theta_{t+j}\right)=\bar{\theta}
$$

where $\hat{b}_{t+j}^{f}$ is the minimum budget voters define in legislative period $t+j$. The left hand side of equation (4) measures the expected utility of the incumbent in the case that she observes $\theta_{t} \leq \hat{b}_{t}^{f}$ in period $t$ and chooses $b_{t}=\hat{b}_{t}^{f}$, so that she becomes reelected at the end of period $t$. The right hand side of equation (4) is the utility of the incumbent if she chooses the maximum budget in period $t$ and is voted out of office at the end of period $t$. Since $\theta_{t}$ is serially uncorrelated and identically distributed over time, the minimum budget assumes the same amount in each period $t$, so that (4) can be written as

$$
\hat{b}^{f}+\frac{\delta}{1-\delta} \hat{b}^{f} F\left(\hat{b}^{f}\right)+\frac{\delta}{1-\delta} \int_{\hat{b}^{f}}^{\bar{\theta}} \theta d F(\theta)=\bar{\theta} .
$$

We are now in a position to state the following result. ${ }^{7}$

Proposition 1 Under full information the equilibrium budget is given by

$$
b^{f}= \begin{cases}\hat{b}^{f}, & \text { if } \quad \theta<\hat{b}^{f} \\ \theta, & \text { if } \quad \theta \geq \hat{b}^{f}\end{cases}
$$

For $\delta<\frac{\bar{\theta}}{\bar{\theta}+E(\theta)}$ the minimum budget satisfies $\hat{b}^{f}>0$ and is implicitly determined by condition (5), where $E(\theta)$ is the expected value of $\theta$ over its full support. For $\delta \geq \frac{\bar{\theta}}{\bar{\theta}+E(\theta)}$ the minimum budget satisfies $\hat{b}^{f}=0$. For $\delta$ approaching to zero, the minimum budget $\hat{b}^{f}$ approaches $\bar{\theta}$.

Figure ?? illustrates the results stated in Proposition 1. The left diagram plots the equilibrium budget $b^{f}$ as a function of the state of nature $\theta$. The right diagram

\footnotetext{
${ }^{7}$ Proofs are relegated to the Appendix.
} 
illustrates how the minimum budget $\hat{b}^{f}$ depends on the discount factor $\delta$. Note that under full information the more patient the incumbent the lower is the rent the electorate has to offer. This ramification has first been identified by Barro(1973).

FIGURE 2

\section{Asymmetric Information Equilibrium}

Under asymmetric information the incumbent observes $\theta_{t}$ in legislative period $t$, whereas voters do not. Voters observe the budget $b_{t}$ and they observe whether the public affairs are handled appropriately because only then they receive the benefit $\phi$ from public finance. As a consequence, voters cannot make the voting rule contingent on $\theta_{t}$, but only on $b_{t}$ and on whether they receive the benefit $\phi$.

Consider the following voting rule. If either the budget $b_{t}$ exceeds a certain cutoff budget $\hat{b}_{t}^{a}$, with superindex $a$ indicating the asymmetric information scenario, or if the budget $b_{t}$ is too small to handle public affairs appropriately (that is, if voters do not receive the benefit $\phi$ from public finance), the incumbent is voted out of office at the end of period $t$. Otherwise, the incumbent is reappointed for another legislative period. Then, if the cutoff budget is properly set, the incumbent will choose $b_{t}=\hat{b}_{t}^{a}$ if she observes $\theta_{t} \leq \hat{b}_{t}^{a}$ and $b_{t}=\bar{\theta}$ if she observes $\theta_{t}>\hat{b}_{t}^{a}$.

The representative voter in period $t$ chooses a cutoff budget that maximizes expected voter welfare, given the budgets in all subsequent periods,

$$
V_{t}=\sum_{j=0}^{\infty} \delta^{j}\left(\phi-b_{t+j}\right) F\left(b_{t+j}\right)+\sum_{j=0}^{\infty} \delta^{j}(\phi-\bar{\theta})\left[1-F\left(b_{t+j}\right)\right]
$$

subject to the constraint, that the incumbent does not find the cutoff budget $\hat{b}_{t}^{a}$ to small so that she chooses $b_{t}=\bar{\theta}$ for all $\theta_{t}$, that is, subject to the constraint

$$
b_{t}+\sum_{j=1}^{\infty} \delta^{j} b_{t+j} F\left(b_{t+j}\right) \geq \bar{\theta} .
$$

As voters minimize the budget, the cutoff budget is determined by

$$
\hat{b}^{a}+\frac{\delta}{1-\delta} \hat{b}^{a} F\left(\hat{b}^{a}\right)=\bar{\theta}
$$


if the constraint does bind. If, in contrast, the constraint does not bind, the cutoff budget is determined by the following first order condition

$$
-F\left(\hat{b}^{a}\right)-\hat{b}^{a} f\left(\hat{b}^{a}\right)+\bar{\theta} f\left(\hat{b}^{a}\right)=0 .
$$

In both cases the cutoff budget chosen by the voters will be the same in all periods so that the index $t$ has again been omitted. The next lemma specifies when $\hat{b}^{a}$ is determined by (6) or by (7), respectively.

Lemma 1 There is some discount factor $\tilde{\delta} \in(0,1)$ so that for $\delta<\tilde{\delta}$ the cutoff budget $\hat{b}^{a}$ is determined by the constraint (6) and for $\delta \geq \tilde{\delta}$ the cutoff budget $\hat{b}^{a}$ is determined by the first order condition (7).

In light of Lemma 1 the equilibrium budget under asymmetric information can be characterized as follows.

Proposition 2 Under asymmetric information, the equilibrium budget is given by

$$
b^{a}=\left\{\begin{array}{ccc}
\hat{b}^{a}, & \text { if } & \theta \leq \hat{b}^{a}, \\
\bar{\theta} & \text { if } & \theta>\hat{b}^{a},
\end{array}\right.
$$

where $\hat{b}^{a}$ is determined by the constraint (6) if $\delta<\tilde{\delta}$ and by the first order condition (7) if $\delta \geq \tilde{\delta}$.

Figure ?? illustrates the result stated in Proposition 2. The left diagram plots the equilibrium budget $b^{a}$ as a function of the state of nature $\theta$. The right digram illustrates how the cutoff budget $\hat{b}^{a}$ depends on the discount factor $\delta$.

FIGURE 3

The next proposition provides a comparison between the full information and the asymmetric information equilibrium.

Proposition $3 b^{a}>b^{f}$ for $\theta \in[0, \bar{\theta}] \backslash\left\{\hat{b}^{a}, \bar{\theta}\right\}$ and $b^{a}=b^{f}$ for $\theta \in\left\{\hat{b}^{a}, \bar{\theta}\right\}$.

The rents resulting from the difference between the two reelection budgets can be seen as a measure of the information rent the incumbent receives in our model. Such a rent has first been identified by Ferejohn (1986). 


\section{Introducing a Fiscal Restraint on the Budget}

Assume now that the electorate can write a fiscal restraint on the public budget into the constitution. We will refer to such a restraint as a budget cap. The constitution states that in each legislative period $t$ the budget $b_{t}$ must not exceed a predefined cap on the budget, denoted as $\bar{b} \leq \bar{\theta}$. In the following we confine attention to the case that information is asymmetrically distributed between voters and the incumbent. 8

In the presence of a budget cap $\bar{b}$, the representative voter chooses a cutoff

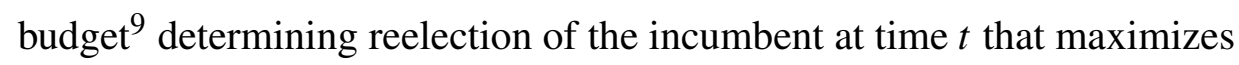

$$
V_{t}=\sum_{j=0}^{\infty} \delta^{j}\left(\phi-b_{t+j}\right) F\left(b_{t+j}\right)+\sum_{j=0}^{\infty} \delta^{j}(\phi-\bar{b})\left[F(\bar{b})-F\left(b_{t+j}\right)\right]-\sum_{j=0}^{\infty} \delta^{j} \bar{b}[1-F(\bar{b})]
$$

subject to

$$
b_{t}+\sum_{j=1}^{\infty} \delta^{j} b_{t+j} F\left(b_{t+j}\right) \geq \bar{b}
$$

If the constraint does bind, the cutoff budget to ensure reelection is determined by

$$
\hat{b}^{c}+\frac{\delta}{1-\delta} \hat{b}^{c} F\left(\hat{b}^{c}\right)=\bar{b} .
$$

where the index $t$ again has been omitted as the voters choose the same cutoff level $\hat{b}^{c}$ in each legislative period, and the superindex $c$ indicates the presence of a constitutional fiscal restraint or budget cap. Equation (8) implicitly defines the reelection cutoff level of spending $\hat{b}^{c}$ as a function of the fiscal restraint level $\bar{b}$ with

$$
\frac{d \hat{b}^{c}}{d \bar{b}}=\frac{1-\delta}{1-\delta+\delta\left[F\left(\hat{b}^{c}\right)+\hat{b}^{c} f\left(\hat{b}^{c}\right)\right]}>0 .
$$

\footnotetext{
${ }^{8}$ Under full information a budget cap will not be used by the electorate if the government cannot go over this budget even if the electorate agrees to the government doing so. If, in contrast, the constitutional rule allows the government to go over the limit if the electorate agrees to a higher budget, then the rent of power can be reduced to zero by a budget cap equal to $\bar{b}=0$. The rule will then be invoked in every period.

${ }^{9}$ We use the term cutoff budget or level, when talking about the reelection policy chosen by voters and we use the term budget cap when referring to the constitutional fiscal restraint.
} 
If the constraint does not bind, the cutoff level in the presence of a fiscal restraint is determined by the following first order condition

$$
-F\left(\hat{b}^{c}\right)-\hat{b}^{c} f\left(\hat{b}^{c}\right)+\bar{b} f\left(\hat{b}^{c}\right)=0
$$

which again implies the cutoff budget as a function $\hat{b}=\hat{b}^{a}(\bar{b})$.

Maximum voter welfare in the presence of a budget cap reads

$$
V=\frac{1}{1-\delta}\left\{\left(\phi-\hat{b}^{c}\right) F\left(\hat{b}^{c}\right)+(\phi-\bar{b})\left[F(\bar{b})-F\left(\hat{b}^{c}\right)\right]-\bar{b}[1-F(\bar{b})]\right\}
$$

where $\hat{b}^{a}$ is either determined by the constraint (8) or by the first order condition (9). Differentiation of $V$ with respect to $\bar{b}$ yields

$$
\frac{d V}{d \bar{b}}=\frac{1}{1-\delta}\left\{\phi f(\bar{b})-1+F\left(\hat{b}^{c}\right)+\left[-F\left(\hat{b}^{c}\right)-\hat{b}^{c} f\left(\hat{b}^{c}\right)+\bar{b} f\left(\hat{b}^{c}\right)\right] \frac{d \hat{b}^{c}}{d \bar{b}}\right\}
$$

where the term in square brackets vanishes if the cutoff budget $\hat{b}^{c}$ is determined by the first order condition (9). This leads us to the following result.

\section{Proposition 4}

$i$. Let $\delta<\tilde{\delta}$. Then, lowering the budget cap $\bar{b}$ starting from $\bar{b}=\bar{\theta}$ increases voter welfare if and only if

$$
\phi f(\bar{\theta})<1-F\left(\hat{b}^{c}\right)-\left[-F\left(\hat{b}^{c}\right)-\hat{b}^{c} f\left(\hat{b}^{c}\right)+\bar{b} f\left(\hat{b}^{c}\right)\right] \frac{d \hat{b}^{c}}{d \bar{b}} .
$$

ii. Let $\delta \geq \tilde{\delta}$. Then, lowering the budget cap $\bar{b}$ starting from $\bar{b}=\bar{\theta}$ increases voter welfare if and only if

$$
\phi f(\bar{\theta})<1-F\left(\hat{b}^{c}\right)
$$

Generally, lowering the budget cap increases voter welfare if the expected marginal costs of a lower budget cap are smaller than the expected marginal benefits. At $\bar{b}=\bar{\theta}$ the expected marginal costs of a lower budget cap are given by $\phi f(\bar{\theta})$ 
per legislative period. Lowering the budget cap implies that it may happen that $\theta$ turns out to be larger than the maximum budget the incumbent is allowed to choose, in which case the public budget will be too small to handle the public affairs appropriately. Then, voters forgo the benefit from public affairs amounting to $\phi$. The marginal likelihood that this happens is given by $f(\overline{\boldsymbol{\theta}})$ when the budget cap is lowered by one currency unit starting from $\bar{b}=\bar{\theta}$.

The expected marginal benefits of a lower budget cap per legislative period depend on whether the constraint on the cutoff budget $\hat{b}^{c}$ is binding or not. This depends on the condition on the discount rate derived in Section 5. Consider first the case that $\delta \geq \tilde{\delta}$ so that the cutoff budget $\hat{b}^{c}$ is determined by the unconstrained solution. If the incumbent observes a $\theta$ that is larger than the cutoff budget $\hat{b}^{c}$, she will choose the maximum budget $\bar{b}$. The probability for this to happen is $1-F\left(\hat{b}^{c}\right)$. Thus, if the budget cap is lowered by one currency unit, the voters receive an expected marginal benefit in the form of a lower maximum budget amounting to $1-F\left(\hat{b}^{c}\right)$.

If $\delta>\tilde{\delta}$, that is, if the cutoff level $\hat{b}^{c}$ is determined by the constrained solution, voters receive an additional marginal benefit of a lower budget cap. In the constrained solution voters actually prefer a lower cutoff budget but are constrained to allow the incumbent a budget sufficiently high so that the incumbent does not choose the maximum budget in all states of nature. Since voters would actually prefer a lower cutoff budget, the term $-F\left(\hat{b}^{c}\right)-\hat{b}^{c} f\left(\hat{b}^{c}\right)+\bar{b} f\left(\hat{b}^{c}\right)$ is negative. This is because the term measures the marginal increase in voter welfare per legislative period if the cutoff level is increased. ${ }^{10}$ If this term was positive, this would imply that $\hat{b}^{c}$ could not be the constrained solution as voters would prefer a higher cutoff level and, at the same time, the incumbent's incentives to choose the maximum budget in all states of nature could be weakened. With a budget cap, the rents the incumbent can extract from holding office by having the opportunity to choose the maximum budget decrease. As a consequence, the budget cap enables voters

\footnotetext{
${ }^{10}$ The argument for $-F\left(\hat{b}^{c}\right)-\hat{b}^{c} f\left(\hat{b}^{c}\right)+\bar{b} f\left(\hat{b}^{c}\right)$ to be negative in the constrained solution does not rely on the assumption that voter welfare is concave for all $b \in[0, \bar{\theta}]$. It simply follows from the fact that in the constrained solution voters are constrained to further lower the cutoff level.
} 
to enforce a lower cutoff level which in the constrained solution increases voter welfare.

Whether the introduction of a budget cap increases expected voter welfare essentially hinges on the distribution of $\theta$. If the density of $\theta$ is thick for large $\theta$, that is, if states of nature are likely to occur in which a large budget is necessary to handle public affairs, the introduction of a budget cap can not be expected to contribute to voter welfare. In contrast, if the density is thin for large $\theta$, a case for a budget cap arises.

The desirability of a budget cap also hinges on the discount factor $\delta$. If the discount factor is small, the incumbent is more inclined to choose the maximum budget irrespective of the state of nature in order to immediately extract the rents from office. A budget cap reduces the maximum budget the incumbent can choose and, thus, weakens her incentives to deploy this strategy. Therefore, the introduction of a budget cap is more likely to be beneficial if the discount factor $\delta$ is small and the constraint on the cutoff budget is binding. ${ }^{11}$

Generally, the budget cap that maximizes voter welfare is determined by the following first order condition

$$
\phi f(\bar{b})-1+F\left(\hat{b}^{c}\right)+\left[-F\left(\hat{b}^{c}\right)-\hat{b}^{c} f\left(\hat{b}^{c}\right)+\bar{b} f\left(\hat{b}^{c}\right)\right] \frac{d \hat{b}^{c}}{d \bar{b}} \leq 0, \quad \text { with } 0=\text { if } \bar{b}<\bar{\theta}
$$

which can be inferred from equation(10). The next result characterizes the properties of an optimal budget cap.

Corollary 1 Let either the condition stated in Proposition 4.i hold for $\delta<\tilde{\delta}$ or the condition stated in Proposition4.ii hold for $\delta \geq \tilde{\delta}$. Then, there exists some budget cap $\bar{b}^{*}$ with $\hat{b}^{c}<\bar{b}^{*}<\bar{\theta}$ that maximizes voter welfare.

\footnotetext{
${ }^{11}$ Note that $\tilde{\delta}$, that is, the discount factor below which the constraint on the cutoff budget $\hat{b}^{c}$ binds, generally depends on the budget cap. This is readily verified as follows. For $\delta=\tilde{\delta}$, equations (8) and (9) imply the same cutoff budget $\hat{b}^{c}$. Together, these two equations then determine the cutoff budget $\hat{b}^{c}$ and the discount factor $\tilde{\delta}$ as functions of the budget cap $\bar{b}$.
} 
The following two examples determine the cutoff budgets without a budget cap, $\hat{b}^{a}$, and with a budget cap, $\hat{b}^{c}$, where condition (11) has been employed to determine the optimal budget cap $\bar{b}^{*}$. The first example is the case where the introduction of a cap is welfare diminishing. In the second example the introduction of a cap is welfare enhancing.

Example 1 Let $\theta$ be uniformly distributed on [0,1]. Then, $\tilde{\delta}=\frac{2}{3}$. For $\delta<\frac{2}{3}$ the cutoff budget is determined by the constrained solution and amounts to $\hat{b}^{a}=$ $\left[\sqrt{1+2 \delta-3 \delta^{2}}-(1-\delta)\right] / 2 \delta>\frac{1}{2}$. For $\delta \geq \frac{2}{3}$ the cutoff budget is determined by the unconstrained solution and amounts to $\hat{b}^{a}=\frac{1}{2}$. In neither case the introduction of a budget cap $\bar{b}<\bar{\theta}$ is beneficial for voters.

Example 2 Let $\theta$ be distributed on $[0,1]$ according to the triangular distribution function $F(\theta)=2 \theta-\theta^{2}$. Then, $\tilde{\delta}=0.672$. The introduction of a budget cap is beneficial for the voters. Table 1 provides numerical solutions of the cutoff budgets with and without a budget cap, $\hat{b}^{a}$ and $\hat{b}^{c}$, and in the presence of an optimal budget cap $\bar{b}^{*}$. In all cases $\phi=1.1$ has been assumed.

\begin{tabular}{lccc}
\hline$\delta$ & $\hat{b}^{a}$ & $\hat{b}^{c}$ & $\bar{b}^{*}$ \\
\hline 0.6 & 0.478 & 0.410 & 0.812 \\
0.9 & 0.423 & 0.405 & 0.947 \\
\hline
\end{tabular}

Table 1: Cutoff budgets and budget caps with triangular distribution

\section{The Role of the Opposition}

The previous section has identified the conditions under with a fiscal restraint in the form of a binding budget cap may be beneficial for voters. The problem with the fiscal restraint is that it may turn out to be too restrictive. This is the case when unfortunate outcomes are likely to happen. Therefore, it is tempting to somehow 
allow the incumbent to choose a budget that exceeds the budget cap if $\theta$ turns out to be larger than the budget cap. Clearly, this must not be at the discretion of the incumbent because then the budget cap is not suited anymore to restrain her budget maximizing attitude. However, as this section demonstrates, there is still an opportunity to fruitfully employ a constitutional fiscal restraint without running into the risk that the government is too restrained to handle unfortunate macroeconomic events appropriately.

In the following we again consider a constitutional rule that imposes a cap on the government budget. We now allow this rule to specify when an exception may apply. We assume that such rules will always require agreement from the opposition, as it is the case in many countries where constitutional rules can only changed with two-third majorities which are very rare. We assume that opposition politicians have the same access to information as the government. While the electorate is still not able to observe $\theta$, the government as well as the opposition are. The opposition hence serves as a second expert who wants to get into power. As indicated earlier, we assume that there are no programmatic differences between the government and the opposition. While our assumption that the government and the opposition have the same access to information about the state of the world may be simplistic, in many countries the opposition has certainly better information than the public due to parliamentary rights and services as well as access to think tanks related to the opposition. Thus, our assumption of access to the same information may serve as a good assumption to get first insights into the effect of rules specifying exceptions to the budget cap.

We ask again, how can the electorate incentivize the government to only apply for exceeding the budget cap if this is necessary, i.e., if $\theta>\bar{b}$. At the same time, we need to ensure that the opposition will only agree to a budget exceeding the cap, if this is necessary to ensure that public affairs can be handled. We study the following voting rule: As before, the representative voter chooses at the beginning of the legislative period a voting rule, that he applies at the end of the period. The government as well as the opposition learn this voting rule. The voting rule 
now specifies certain reelection of the incumbent if the budget does not exceed a reelection cutoff and the public affairs are handled. If the government exceeds the cutoff and does not apply to exceed the constitutional budget cap, the incumbent loses office for sure and the opposition takes over. If the government applies for exceeding the budget cap, the opposition has to decide whether it agrees or not. If it does not agree and the government sets a budget equal to the budget cap but fails to handle public affairs, then the incumbent stays in office. If public affairs can be handled with a budget smaller or equal to $\bar{b}$ then the opposition gets elected. If the opposition agrees and the government sets a budget above $\bar{b}$ and the government is able to handle public affairs then the incumbent will be reelected in period $t$ with probability $p_{t}$ and with probability $1-p_{t}$ the opposition gets into power.

This rule provides the incumbent with the incentive to apply for exceeding the budget, i.e., $b=\bar{\theta}$ if $\theta>\bar{b}$. The opposition has an incentive to agree if and only if this is the case. The voting rule differs from the rule above as it now specifies a probability $p_{t}$ of reelection in the case that the government applies for a budget exceeding the cap and the opposition agrees and public affairs are handled appropriately.

The representative voter at time $t$ chooses a cutoff budget and a probability $p_{t}$ to maximize his utility

$$
\begin{gathered}
V_{t}=\sum_{j=0}^{\infty} \delta^{j}\left(\phi-b_{t+j}\right) F\left(b_{t+j}\right)+\sum_{j=0}^{\infty} \delta^{j}(\phi-\bar{b})\left[F(\bar{b})-F\left(b_{t+j}\right)\right] \\
+\sum_{j=0}^{\infty} \delta^{j}(\phi-\bar{b})[1-F(\bar{b})]
\end{gathered}
$$

subject to the constraint

$$
b_{t}+\sum_{j=1}^{\infty} \delta^{j} b_{t+j} F\left(b_{t+j}\right)+\sum_{j=1}^{\infty} \delta^{j} p_{t+j-1} \bar{\theta}[1-F(\bar{b}) \geq \bar{b} .
$$

Obviously, the constraint becomes less binding if $p_{t}$ is larger. Therefore, voters will choose the highest possible probability $p_{t}$ to reelect the incumbent in the case that the incumbent requests the budget $b_{t}=\bar{\theta}$ and the opposition approves. Given 
that any positive probability suffices to incentivize the opposition to agree if a high budget is required, voters will choose a $p_{t}$ arbitrarily close to 1 . For simplicity we assume $p_{t}=1$ for all $t$. Then, the cutoff budget is determined by

$$
\hat{b}^{o}+\frac{\delta}{1-\delta} \hat{b}^{o} F\left(\hat{b}^{o}\right)+\frac{\delta}{1-\delta} \bar{\theta}[1-F(\bar{b})]=\bar{b},
$$

if the constraint binds, and by

$$
-F\left(\hat{b}^{o}\right)-\hat{b}^{o} f\left(\hat{b}^{o}\right)+\bar{b} f\left(\hat{b}^{o}\right)=0
$$

if not. Again, the time index $t$ has been omitted as voters are concerned with the same calculus in each legislative period $t$. The superindex $o$ indicates a cutoff level chosen by the voter in the presence of a budget cap that can be exceeded if approved by the opposition. Conditions (12) and (13) both determine the cutoff budget $\hat{b}^{o}$ as a function of the budget cap $\bar{b}$. In case that the cutoff budget is determined by (12), that is, if is determined by the constraint on the cutoff, implicit differentiation yields

$$
\frac{d \hat{b}^{o}}{d \bar{b}}=\frac{1+\delta f(\bar{b})}{1-\delta+\delta\left[F\left(\hat{b}^{c}\right)+\hat{b}^{c} f\left(\hat{b}^{c}\right)\right]}>0 .
$$

The maximum voter welfare that can be achieved given the presence of a budget cap that can be relaxed if the opposition agrees is now given as

$$
V=\frac{1}{1-\delta}\left\{\left(\phi-\hat{b}^{o}\right) F\left(\hat{b}^{o}\right)+(\phi-\bar{b})\left[F(\bar{b})-F\left(\hat{b}^{o}\right)\right]+(\phi-\bar{\theta})[1-F(\bar{b})]\right\},
$$

where $\hat{b}^{o}$ is either determined by the constraint (12) or by the first order condition (13). Differentiation of $V$ with respect to $\bar{b}$ yields

$$
\begin{aligned}
\frac{d V}{d \bar{b}}=\frac{1}{1-\delta} & \left\{-F(\bar{b})+F\left(\hat{b}^{o}\right)+(\bar{\theta}-\bar{b}) f(\bar{b})\right. \\
+ & {\left.\left[-F\left(\hat{b}^{o}\right)-\hat{b}^{o} f\left(\hat{b}^{o}\right)+\bar{b} f\left(\hat{b}^{o}\right)\right] \frac{d \hat{b}^{o}}{d \bar{b}}\right\}, }
\end{aligned}
$$

where again the term in square brackets is negative if the cutoff budget $\hat{b}^{o}$ is determined by the constraint (12) and vanishes if the cutoff budget $\hat{b}^{o}$ is determined by the first order condition (13). From (14) the following inference can be drawn. 
Proposition 5 The introduction of a budget cap $\bar{b}$ that can only be exceeded by the incumbent if approved by the opposition always increases voter welfare.

Proposition 5 implies that in the case that the budget cap $\bar{b}$ can only be exceeded if approved by the opposition, an optimal budget cap $\bar{b}^{*}$ exists for all distributions of $\theta$ and all $\phi>\bar{\theta}$. The optimal budget cap satisfies $\hat{b}^{o}<\bar{b}^{*}<\bar{\theta} .{ }^{12}$ Figure ?? illustrates the equilibrium budget if a budget cap amounting to $\bar{b}^{*}$, which can only be exceeded if approved by the opposition, is written in the constitution.

FIGURE 4

For $\theta \in\left[0, \hat{b}^{o}\right]$ the incumbent chooses the budget $b=\hat{b}^{o}$ and is reelected for another term in office, for $\theta \in\left(\hat{b}^{o}, \bar{b}^{*}\right]$ the incumbent chooses the budget $b=\bar{b}^{*}$ and is thrown out of office, and for $\theta \in\left(\bar{b}^{*}, \bar{\theta}\right]$ the incumbent chooses the budget $b=\bar{\theta}$ and is reelected for another term in office with probability $p$ arbitrarily close to 1 . Clearly, the levels of $b=\hat{b}^{o}$ and $b=\bar{b}^{*}$ depend on the distribution of $\theta$ and on the discount factor $\delta$. The following example continues Example ?? above and determines the optimal cutoff budget and the budget cap for the case of a uniform distribution, where the introduction of a budget cap was welfare diminishing without the exception mechanism.

Example 3 Let $\theta$ be uniformly distributed on [0,1]. In this case $\tilde{\delta}=\frac{3}{7}$ if the budget cap is chosen optimally. For $\delta<\frac{3}{7}$ the cutoff budget $b=\hat{b}^{o}$ falls from $\frac{1}{2}$ to $\frac{1}{3}$ with increasing $\delta$ and the optimal budget cap $b=\bar{b}^{*}$ increases from $\frac{1}{2}$ to $\frac{2}{3}$. For $\delta \geq \frac{3}{7}$ the cutoff budget $b=\hat{b}^{o}$ becomes $\frac{1}{3}$ and the optimal budget cap $b=\bar{b}^{*}$ becomes $\frac{2}{3}$. Figure ?? illustrates this example.

\section{FIGURE 5}

The intuition why a fiscal restraint with an exception requiring the opposition's agreement always improves welfare is that the opposition, having access to information as good as that of the government, serves as a second expert in case the state of the world requires very high spending levels. This eliminates the cost of the fiscal restraint in cases of very high budgetary requirements.

\footnotetext{
${ }^{12}$ The proof is similar to the proof of Corollary 1 .
} 


\section{Conclusions}

In this article we have shown that introducing a fiscal restraint on the public budget can be welfare enhancing even if voters are fully rational and no intergenerational or international externalities exist. Our argument is based on the assumption of politicians serving as experts. Access to more and better information or simply specialization allows elected politicians to aggregate and interpret information such that they have better information than the electorate about the funds needed to handle public affairs and/or to avoid a crisis. The electorate, on the other hand, can only observe the budget and whether public affairs are handled, but no what funds are needed to do so. We have shown that very strict constitutional rules are welfare enhancing if the need for very high budgets is relatively rare. If high budgets may be frequent then any constitutional rule will lead to welfare losses and only if it is amended by rules allowing for exceptions can this be an instrument to enhance welfare for sure.

Our article presents a novel perspective on the need for government control given agency problems and the often discrete loss of a too tight level of control the government may fail to deliver. We have shown that rules for reelection can serve to some extent to incentivize governments to limit spending and that fiscal restraints can decrease these agency costs further by limiting spending in periods where politicians know to lose office. The cost is that in some situations, call it a crisis, the government may not be able to access the funds to handle public affairs.

Our model also implies a political business cycle. If the reign of a government comes to its end, or if it is likely to be voted out of power, it will increase spending. We share with Rogoff (1990) the fact that such behavior follows from the agency problem a rational electorate faces when it tries to incentivize politicians and it is not due to the fact of myopia or limited rationality of the electorate as in older models of the political cycle (see, e.g., Nordhaus, 1975). In these models, government spending will increase, in particular if an election is close, because the incumbent will spend heavily on observable government expenditure to increase her chance to stay in power. In our model, government spending is high, 
because the increased risk of losing power in a tight election implies that politicians go for the immediate utility of an increased budget instead of an uncertain future in office. Aidt et al (2011) show that tight margins in elections are correlated with increased spending. Unfortunately, it is not possible to tell whether the high spending increases the chance to lose office or whether it indeed increases the incumbents probability to stay in office. Litchig and Morrison (2010) report on Brazilian local government elections where the voting rules do not allow an incumbent to be reelected and find increased spending caused by a change in federal funding for local government. This spending leads to better education and health outcomes, i.e. it seems not to be pure waste, as it should be in light of our theory.

One assumption made to allow for a consistent argument with respect to the rationality of the voting rule at the end of the legislative period is that for the electorate to be indifferent between the incumbent and the opposition, the electorate only cares about the size of the budget. If one relaxes this assumption, the reelection rule set at the beginning of the legislative period would not be rational after the budget has been revealed as in this case voters have an additional incentive to keep the incumbent in power. A simple modification to capture a situation where the opposition has a different political platform would be to assume a one-off cost of changing government, i.e., it is not continuous spending where parties differ but some big projects that they propose. In such a model, the rents from power are increased and as such our argument for a budget cap still prevails. 


\section{Appendix}

\section{Proof of Proposition 1}

Implict differentiation of equation (5) yields

$$
\frac{d \hat{b}^{f}}{d \delta}=-\frac{\hat{b}^{f} F\left(\hat{b}^{f}\right)+\int_{\hat{b}^{f}}^{\bar{\theta}} \theta d F(\theta)}{(1-\delta)\left[1-\delta+\delta F\left(\hat{b}^{f}\right)\right]}<0 .
$$

Furthermore, equation (5) implies that $\hat{b}^{f} \rightarrow \bar{\theta}$ if $\delta \rightarrow 0$. Finally, setting $\hat{b}^{f}=0$ in equation (5), one gets after some manipulations

$$
\delta=\frac{\bar{\theta}}{\bar{\theta}+E(\theta)} .
$$

Since the minimum budget $\hat{b}^{f}$ cannot be negative, it follows that $\hat{b}^{f}=0$ for all $\delta \geq \frac{\bar{\theta}}{\bar{\theta}+E(\theta)}$. Q.E.D.

\section{Proof of Lemma 1}

First observe that if $\hat{b}^{a}$ as determined by (7) is larger than $\hat{b}^{a}$ as determined by (6), the constraint on $\hat{b}$ does not bind. Second, observe that $\hat{b}^{a}$ as determined by (7) is independent of $\delta$, whereas $\hat{b}^{a}$ as determined by (6) depends on $\delta$ as follows

$$
\frac{d \hat{b}^{a}}{d \delta}=-\frac{\hat{b}^{a} F\left(\hat{b}^{a}\right)}{(1-\delta)\left[1-\delta+\delta\left[F\left(\hat{b}^{a}\right)+\hat{b}^{a} f\left(\hat{b}^{a}\right)\right]\right]}<0 .
$$

Third observe that $\hat{b}^{a}$ as determined by (7) implies $\hat{b}^{a}<\bar{\theta}$. Fourth and finally observe that $\hat{b}^{a}$ as determined by (6) implies that $\hat{b}^{a} \rightarrow \bar{\theta}$ if $\delta \rightarrow 0$ and $\hat{b}^{a} \rightarrow 0$ if $\delta \rightarrow 1$. Q.E.D.

\section{Proof of Proposition 3}

Since $\hat{b}^{a}$ is bounded from below by condition (6) and $\hat{b}^{a}$ as determined by condition (6) exceeds $\hat{b}^{f}$ as determined by condition (5), it follows that $\hat{b}^{a}>\hat{b}^{f}$. Thus, for $\theta<\hat{b}^{f}$ it follows that $b^{a}=\hat{b}^{a}>b^{f}=\hat{b}^{f}$. For $\theta \in\left[\hat{b}^{f}, \hat{b}^{a}\right)$ it follows that $b^{a}=\hat{b}^{a}>b^{f}=\theta$. For $\theta \in\left(\hat{b}^{a}, \bar{\theta}\right)$ it follows that $b^{a}=\bar{\theta}>b^{f}=\theta$. Only for $\theta \in\left\{\hat{b}^{a}, \bar{\theta}\right\}$ it follows that $b^{a}=b^{f}$. 


\section{Proof of Corollary 1}

From Proposition 4 it is obvious that $\bar{b}^{*}<\bar{\theta}$. For $\delta<\tilde{\delta}$, the cutoff budget $\hat{b}^{c}$ is determined by the constraint (8) and $\hat{b}^{c}<\bar{b}^{*}$ directly follows from the fact that $F\left(\hat{b}^{c}\right)>0$. For $\delta \geq \tilde{\delta}$ the cutoff budget $\hat{b}^{c}$ is determined by the the first order condition (9). Assume, contrary to Corollary 1 , that $\hat{b}^{c} \geq \bar{b}^{*}$. Then, it follows that

$$
-F\left(\hat{b}^{c}\right)-\left(\hat{b}^{c}-\bar{b}^{*}\right) f\left(\hat{b}^{c}\right)<0
$$

which is contradictory to condition (9). Q.E.D.

\section{Proof of Proposition 5}

Evaluate (14) at $\bar{b}=\bar{\theta}$ to find that

$$
\left.\frac{d V}{d \bar{b}}\right|_{\bar{b}=\bar{\theta}}<0
$$

if

$$
-F(\bar{\theta})+F\left(\hat{b}^{o}\right)+\left[-F\left(\hat{b}^{o}\right)-\hat{b}^{o} f\left(\hat{b}^{o}\right)+\bar{b} f\left(\hat{b}^{o}\right)\right] \frac{d \hat{b}^{o}}{d \bar{b}}<0 .
$$

The term in square brackets is negative if $\hat{b}^{o}$ is determined by the constraint (12) and vanishes if $\hat{b}^{o}$ is determined by the first order condition (13). Further, $F(\bar{\theta})>$ $F\left(\hat{b}^{o}\right)$ and $d \hat{b}^{o} / d \bar{b}>0$ if $\hat{b}^{o}$ is determined by the constraint (12). Thus, it follows that $d V / d \bar{b}<0$ for $\bar{b}=\bar{\theta}$. Q.E.D. 


\section{References}

Aidt, T., F. Veiga and L. Veiga (2011), Election Results and Opportunistic Policies: A New Test of the Rational Political Business Cycle Model, Public Choice, $148,21-44$.

Barro, R.J. (1973), The Control of Politicians: An Economic Model, Public Choice, $14,19-42$.

Besley, T. and M. Smart (2007), Fiscal Restraints and Voter Welfare, Journal of Public Economics, 91, 755-773.

Brennan, G. and J.M. Buchanan (1980), The Power to Tax: Analytical Foundations of a Fiscal Constitution, Cambridge: Cambridge University Press.

Buchanan, J.M. (1967), Public Finance in Democratic Process: Fiscal Institutions and Individual Choice, Durham, NC: University of North Carolina Press.

Buchanan, J. M. and G. Tullock (1962), The Calculus of Consent, Ann Arbor: University of Michigan Press.

Darby, M.R. and E. Karni (1973), Free Competition and the Optimal Amount of Fraud, Journal of Law and Economics, 16, 67-88.

Dulleck, U. and R. Kerschbamer (2006), On Doctors, Mechanics, and Computer Specialists: The Economics of Credence Goods, Journal of Economic Literature, 44, 5-42.

Dulleck, U., Kerschbamer, R. and Sutter, M. (2011), The Economics of Credence Goods: On the Role of Liability, Verifiability, Reputation and Competition, American Economic Review, 101, 526-555.

Ferejohn, J. (1986), Incumbent performance and electoral control, Public Choice $50,5-25$.

Hagen, J. von and B. Eichengreen (1996), Federalism, Fiscal Restraints, and European Monetary Union, American Economic Review, Papers and Proceedings, $86,134-138$.

Litchig S. and K. Morrison (2010), Government Spending and Re-election: QuasiExperimental Evidence from Brazilian Municipalities, Barcelona GSE Working 
Papers Series No. 515.

Niskanen, W.A. (1971), Bureaucracy and Representative Government, Chicago: Aldine Atherton.

Nordhaus, W.D. (1975), The Political Business Cycle, Review of Economic Studies, 42, 169-190.

Persson, T., G. Roland and G. Tabellini (1997), Separation of Powers and Political Accountability, Quarterly Journal of Economics, 112, 1163-1202,

Persson, T. and L.E.O. Svensson (1989), Why a Stubborn Conservative Would Run a Deficit: Policy with Time-Inconsistent Preferences, Quarterly Journal of Economics, 104, 325-45.

Rogoff, K. (1990), Equilibrium Political Budget Cycles, American Economic Review, 80, 21-36.

Schick, A. (2010), Post-Crisis Fiscal Rules: Stabilising Public Finance while Responding to Economic Aftershocks, OECD Journal on Budgeting, 10, 1-18

Tabellini, G. and A. Alesina (1990), Voting on the Budget Deficit, American Economic Review 80, 37-49,

Wilson, J.D. (1989), An Optimal Tax Treatment of Leviathan, Economics and Politics 1, 97-117.

Yared, P. (2010), Politicians, Taxes and Debt, Review of Economic Studies, 77, 806-840. 